ISSN 0258-7122

Bangladesh J. Agril. Res. 39(4): 605-619, December 2014

\title{
SCREENING OF CHICKPEA GENOTYPES AGAINST SALINITY STRESS
}

\author{
MD. SHAHEENUZZAMN ${ }^{1}$
}

\begin{abstract}
The experiment was conducted during the period from December 13, 2010 to May 13, 2011 at the Crop Physiology Lab, Agronomy Division, Bangladesh Agricultural Research Institute (BARI). In Hoagland culture solution, 70 (Seventy) genotypes of chickpea were tested during germination and seedling stage at $0,5,10$ and $15 \mathrm{dS} / \mathrm{m}$ salinity levels. Distilled water $(0 \mathrm{dS} / \mathrm{m})$ was used as a control. Germination percentage (GP), relative germination percentage (RGP), germination rate (GR), relative germination rate (RGR), root length (RL), relative root length (RRL), shoot length (SL), relative shoot length (RSL), vigor index, total dry matter (TDM) and relative total dry matter (RTDM) were found to be affected by salinity. Genotypes BD-6061, BD-6066 BD-6071, BD6060, BD-6067 and BD 6078 performed better at $10 \mathrm{dS} / \mathrm{m}$ and survived up to 15 days after germination as evaluated on the basis of germination percentage (GP), relative germination percentage (RGP), total dry matter (TDM) and relative total dry matter (RTDM). These genotypes could be selected for further investigation under pot culture and field evaluation in the saline area.
\end{abstract}

Keywords: Chickpea, Genotype, Salinity level, Hongland and Pot culture

\section{Introduction}

Out of 2.85 million hectares of the coastal and offshore areas about 1.06 million hectares are saline with various magnitudes, which cover over $30 \%$ of the total cultivable lands of Bangladesh. Agricultural land use in these areas is very poor, which is roughly $50 \%$ of the country's average (Petersen and Shireen, 2001). Salinity causes unfavorable environment and hydrological situation that restrict normal crop production during the dry season. In general, soil salinity is believed to be mainly responsible for low land use as well as cropping intensity in the area (Rahman and Ahsan, 2001). Soil salinity problem in the country received very little attention in the past. Increased pressure of growing population demand more food. Thus it has become increasingly important to explore the possibilities of increasing the potential of these (saline) lands for increased production of crops.

Chickpea (Cicer arietinum L.) is the fifth most extensively planted grain legume (D'amorea et al., 1996). Besides being an important source of human and

${ }^{1}$ Scientific Officer, Agronomy Division, Bangladesh Agricultural Research Institute (BARI), Joydebpur, Gazipur-1701. Bangladesh. 
animal food, the crop also plays an important role in the maintenance of soil fertility, particularly in southern regions (Saxena, 1990). A major constraint on chickpea production in coastal area is soil salinity, predominately due to chloride and sulphate accumulation in saline area. Although some soils are naturally saline, the secondary salinization is largely brought about by the use of irrigation systems, that is the greatest threat to legume sustainability in southeast regions, where water supplies are limited and irrigation is essential to improve poor crop yields. As with many other pulses, chickpea is a salt-sensitive crop and yields are seriously reduced particularly by chloride salinity (Manchanda and Sharma, 1990.) The effects of salinity on chickpea are wide ranging. Seed germination is delayed and reduced and vegetative plant growth is suppressed under saline conditions (Sharma et al., 1982; Yadav et al., 1989). Recent strategies of Bangladesh Agricultural Research Institute is to develop salt tolerant genotype of Chickpea to cope with the need of the country for better utilization of salt affected areas by fitting salt tolerant genotypes. The objective of this experiment was to evaluate genotypes of Chickpea for their salt tolerance.

\section{Materials and Method}

The experiment was conducted during the period from December 13, 2010 to May 13, 2011 at the Crop Physiology Lab, Agronomy Division, Bangladesh Agricultural Research Institute (BARI). Seeds of seventy genotypes of chickpea were collected from Plant Genetics Resource Center (PGRC), BARI, Joydebpur, Gazipur and subjected to attain different salinity levels. The experiment assessed the germination and seedling growth of chickpea genotypes at different $\mathrm{NaCl}$ salinity levels. The $\mathrm{NaCl}$ concentrations used were 0 (control), 5, 10, and 15 $\mathrm{dS} / \mathrm{m}$ and 70 genotypes were used as treatment variables. The salt solution was prepared by calculating amount of normal $\mathrm{NaCl}$ in distilled water. Hongland solution was used as nutrient media with the salt solution. The $\mathrm{P}^{\mathrm{H}}$ of Hongland solution was maintained 6-7. Plastic pots were used in the experiment with a diameter of $10 \mathrm{~cm}$ and arranged in a completely randomized design with three replications. Each pot was supplied with $500 \mathrm{ml}$ of the respective treatment solution. Seeds were sown on the plastic pots having bolting paper. The germination count was started after 72 hours of sowing and continued till the $13^{\text {th }}$ day. A seed was considered to have germinated when both the plumule and the radicle emerged $>0.5 \mathrm{~cm}$. After 15 days, the shoot and the root length of ten randomly selected seedlings from each replicate were measured following a draftsman ruler (Azhar and McNeilly, 1987). 
Germination rate (GR): the average number of days needed for plumule or radicle emergence was calculated as (Lemma Desalegne, 1996):

$$
\text { Germination Rate }=\frac{\mathrm{NTn} 3+\mathrm{NTn} 6+\mathrm{NTn} 9+\mathrm{NTn} 12}{\text { Total number of seeds germinated }}
$$

Where: $\mathrm{Tn}=$ number of seeds germinated at day $3,6,9,12$

$\mathrm{N}=$ days $(3,6,9,12)$

The plants were then collected from the pots and the following measurements were done

i. $\quad$ Root height $(\mathrm{cm})$.

ii. Shoot height $(\mathrm{cm})$

iii. Shoot to root ratio

iv. Vigor index

v. Oven dry-weight of plant (g).

Relative indices were calculated as follows:

Relative Germination Percentage $($ RGP $)=\frac{\text { Germination of stressed seedlings } \times 100}{\text { Seedling height of control seedlings }}$

Relative Germination Percentage $(\mathrm{RGP})=\frac{\text { Germination of stressed seedlings } \times 100}{\text { Seedling height of control seedlings }}$

RelativeT otalDry Matter $=\frac{\text { Dry }- \text { matterof stressed seedlings } \times 100}{\text { Dry }- \text { matterof controlseedlings }}$

\section{Statistical Analysis}

Data analysis was carried out by SAS package where two way analysis of variance (ANOVA) and correlation analysis were employed. Prior to data analysis, shoot-to-root ratio (SRR) was $\log$ transformed. At $15 \mathrm{dS} / \mathrm{m}$, almost all genotypes of chickpea were collapsed after germination. Consequently, the incomplete data obtained from these salinity levels had been excluded from the data. Analysis of germination percentage (GP), relative germination percentage (RGP), germination rate (GR), relative germination rate (RGR), root length (RL), relative root length (RRL), shoot length (SL), relative shoot length (RSL), total dry matter (TDM) and relative total dry matter (RTDM) were measured. 


\section{Results and Discussion}

\section{Germination Percentage}

At different salinity levels, the germination percentage (GP) and the relative germination percentage (RGP) were shown in Fig.1 and Fig 2. A variation in the germination of chickpea genotypes under salinity was observed. $\mathrm{NaCl}$ salinity stress decreased the rate of germination percentage at higher salinity level (15 dS $/ \mathrm{m})$. It was observed from Fig. 1 and Fig. 2 that at salinity level $(10 \mathrm{dS} / \mathrm{m})$, the genotypes BD-6060, BD-6071, BD-6078, BD-6080, BD-6084, BD-6089, BD6093, BD-6094, BD-6095, BD-6184, BD-6296 and BD-6309 showed higher (50$60 \%)$ germination percentage. On the other hand, the genotypes BARI Chola-3, BARI Chola-4, BARI Chola-6, BARI Chola-7, BD-6035, BD-6040, BD-6041, BD-6046 and BD-6045 gave lower germination percentage. The genotypes BD-6089, BD-6093, BD-6094, BD-6095, BD-6108, BD-6208, BD-6284, BD6289, BD-6295 and BD-6296 gave 30-50 \% germination and lower RGP (\%) at $15 \mathrm{dS} / \mathrm{m}$. Salinity level resulted in reduced germination percentage in all most all genotypes. Similar results were reported in Mungbean (Mahajan andTuteja, 2005; Mahadavi and Sanavy, 2007), Pea (Shahid et al., 2012), rice (Lee et al., 1998), durum wheat and tef (Tekalign Mamo et al., 1996). Salt stress delayed the rate of germination. The effect being more pronounced at higher salinity levels. This is in agreement with reports in intermediate wheat grass (Hunt, 1965), spring wheat (Ashraf and McNeilly, 1988), pearl millet (Singh et al., 1999), perennial rye grass (Horst and Dunning, 1989), and sorghum (Marambe and Ando, 1995).

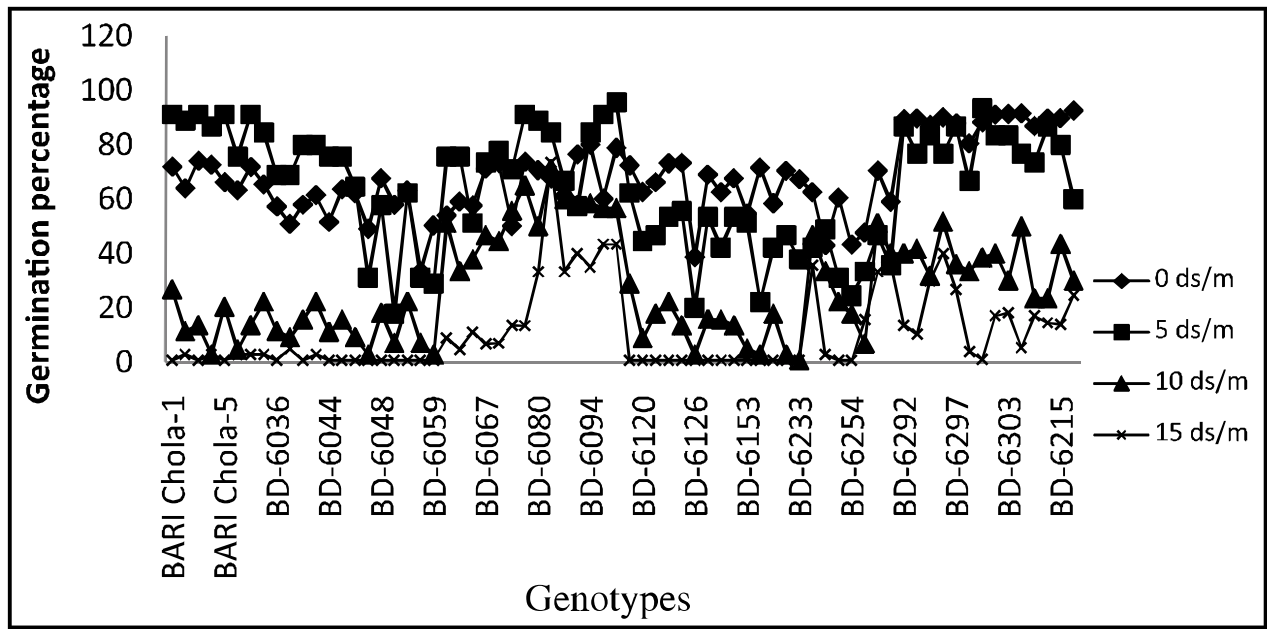

Fig. 1. Effect of salinity levels on germination percentage of chickpea genotypes. 


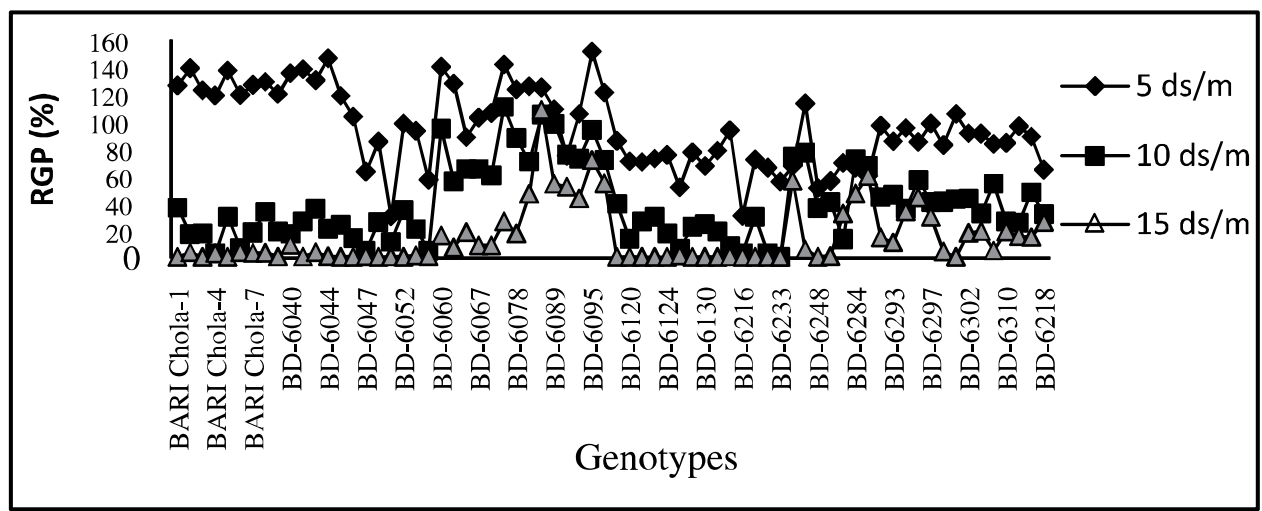

Fig. 2. Relative germination percentage of chickpea genotypes as affected by salinity stress.

\section{Germination Rate (GR)}

The highest germination rate (7.8) was found in genotype BD-6040 followed by BARI Chola-1 (7.5), BARI Chola-2 (7.54), BARI Chola-3 (7.51), BD-6041(7.66), BD-6044 (7.52) and BD-6048 (7.58) at higher level of salinity (10 dS/m). The lowest germination rate was found in genotype BD-6068 (6.48) followed by BD6117 (6.66), BD-6126 (6.70), BD-6093 (6.70), BD-6129 (6.70) and BD-6122 (6.74) at same level of salinity on the basis of germination rate (Fig. 4) and relative germination rate (RGR) was reduced at (15 dS/m) of salinity (Fig. 5).

The rate of germination was decreased with increasing salinity levels. The results agreed with those of Kumar et al. (1981), Abel and Macenzle (1964), Paliwal and Maliwal (1972), Al-Moaikal (2006), Varshney and Baijal (1977) and Basalah (1991) who reported that salinity decreased the rate of germination and emergence.

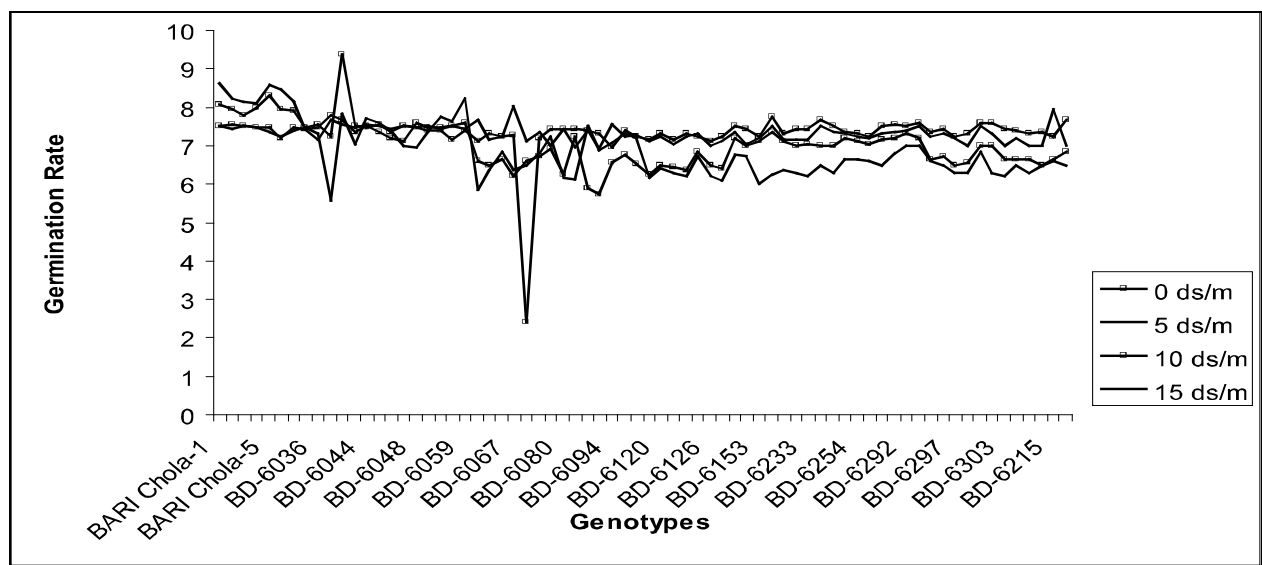

Fig. 3. Effect of different salinity levels on germination rate of chickpea geotypes. 


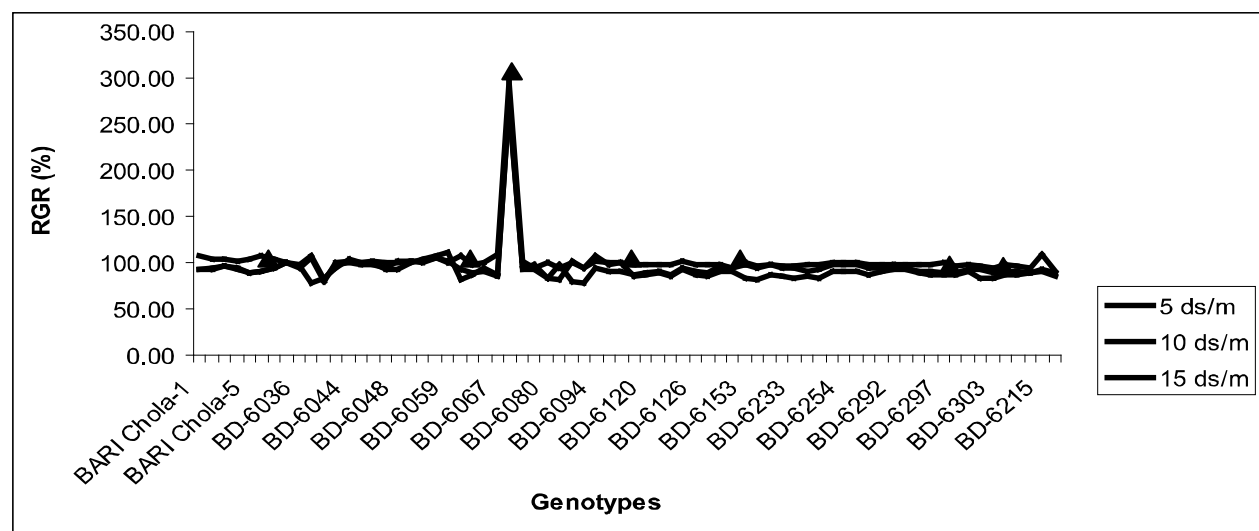

Fig. 4. Effect of salinity on relative germination rate of chickpea genotypes.

\section{Seedling Root Length}

The highest seedling root length (SRL) was found in genotype BD-6284 (12.52 $\mathrm{cm})$ followed by BD-6078 $(10.50 \mathrm{~cm})$, BARI Chola-7, BD-6042, BD-6045, BD6060, BD-6084, BD-6117, BD-6130 and BD-6245 at $10 \mathrm{dS} / \mathrm{m}$ (Fig. 5). Increasing salinity levels decreased the plant relative root length (Fig. 6) as observed in the study.

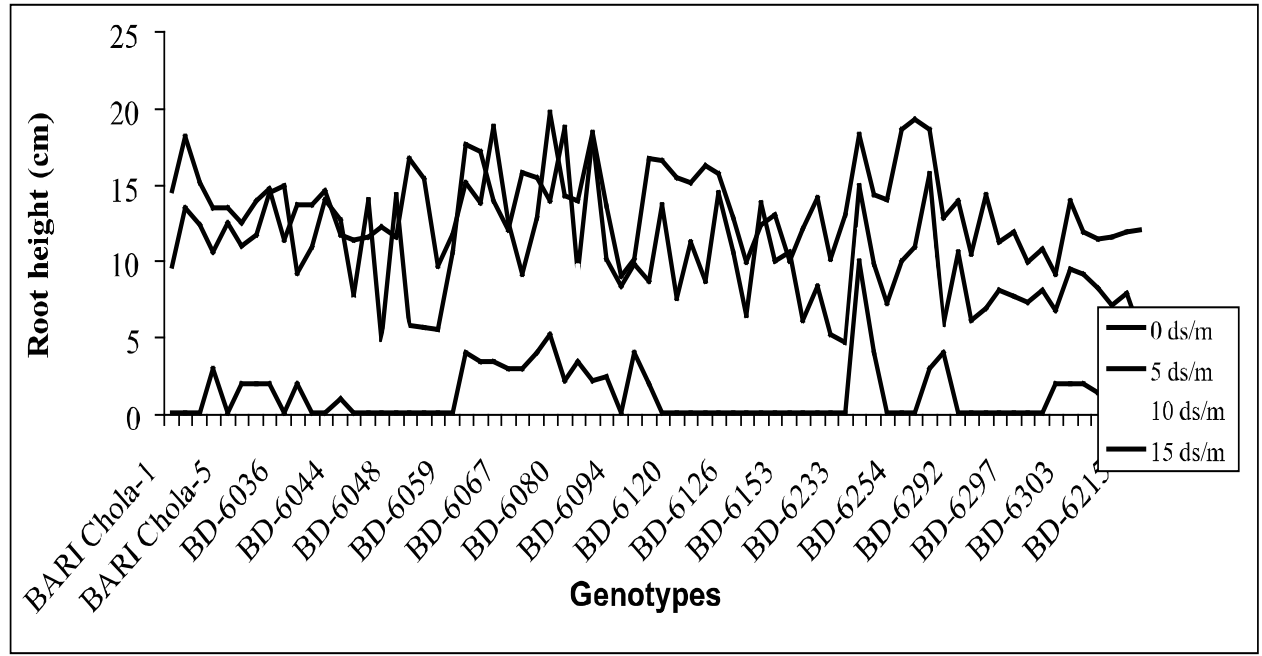

Fig. 5. Effect of salinity levels on root length $(\mathrm{cm})$ of chickpea genotypes. 


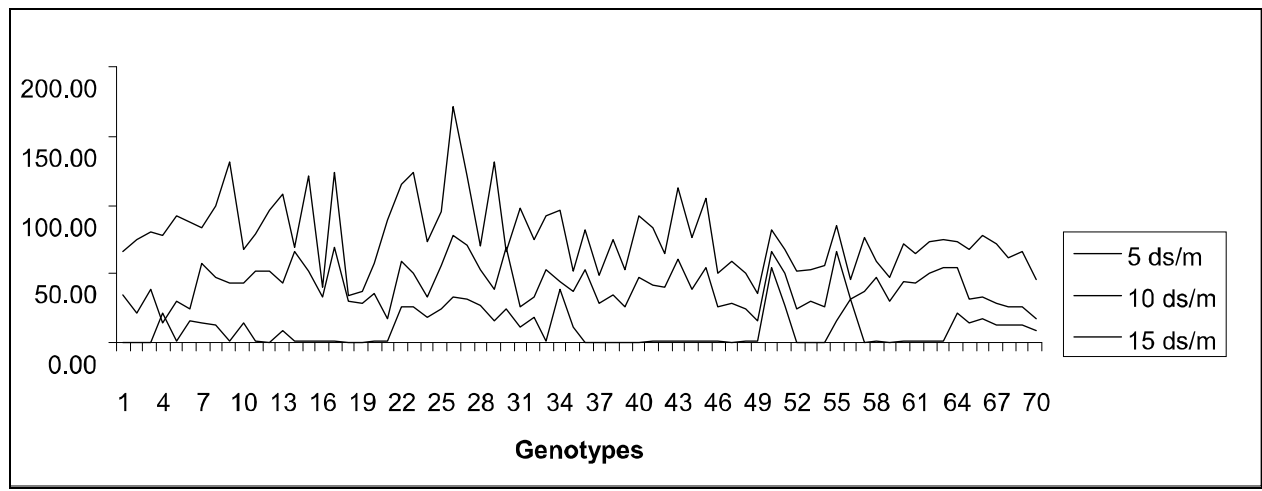

Fig. 6. Relative root length of Chickpea genotypes as affected by salinity stress.

\section{Seedling Shoot Length}

The highest seedling shoot length (SSL) was found in genotype BD-6208 (15.50 $\mathrm{cm})$ followed by BD-6295, BD-6303, BD-6060, BD-6066, BD-6067, BD-6071, BD-6078, BD-6080, BD-6084, BD-6284, BD-6292, BD-6295, BD-6226 and BD6297 at $10 \mathrm{dS} / \mathrm{m}$. The lowest seedling shoot length was found in genotype BARI Chola-4 followed by BARI Chola-3, BD-6035, BD-6216 and BD-6094 (Fig. 8). At $15 \mathrm{dS} / \mathrm{m}$ salinity level, most of the genotypes were failed to survive up to 15 days except BD-6060, BD-6061, BD-6066, BD-6068, BD-6071, BD-6078, BD6080, BD-6084, BD-6089, BD-6093, BD-6284, BD-6289, BD-6302, BD-6303, BD-6309, and BD-6310. The relative shoot length (RSSL) was reduced with increasing salinity levels (Fig. 8).

The root and shoot lengths are the most important parameters for salt stress because roots are in direct contact with soil and absorb water from soil and shoot supply it to the rest of the plant. For this reason, root and shoot length provides an important clue to the response of plants to salt stress (Jamil and Rha, 2004). Salt stress inhibited the seedling growth (root and shoot length) but root length was more affected than shoots length .Inhibition of plant growth by salinity might be due to the inhibitory effect of ions. The reduction in root and shoot development may be due to toxic effects of the $\mathrm{Na}^{+}$and $\mathrm{Cl}^{-}$used as well as unbalanced nutrient uptake by the seedlings. Higher salinity may inhibit root and shoot elongation due to slowing down the water uptake by the plant (Werner and Finkelstein, 1995) and might be another reason for this decrease. Neumann (1995) indicated that salinity can rapidly inhibit root growth and hence capacity of water uptake and essential mineral nutrition from soil. From the study, it was found that salt stress inhibited the growth of root more than shoot in all chickpea genotypes. The findings of the present study are in accord with findings of Demir 
and Arif (2003) who reported that the root growth was more adversely affected compared to shoot growth by salinity. Hussain and Rehman (1997) also reported that the roots of seedling were more sensitive than the shoots.

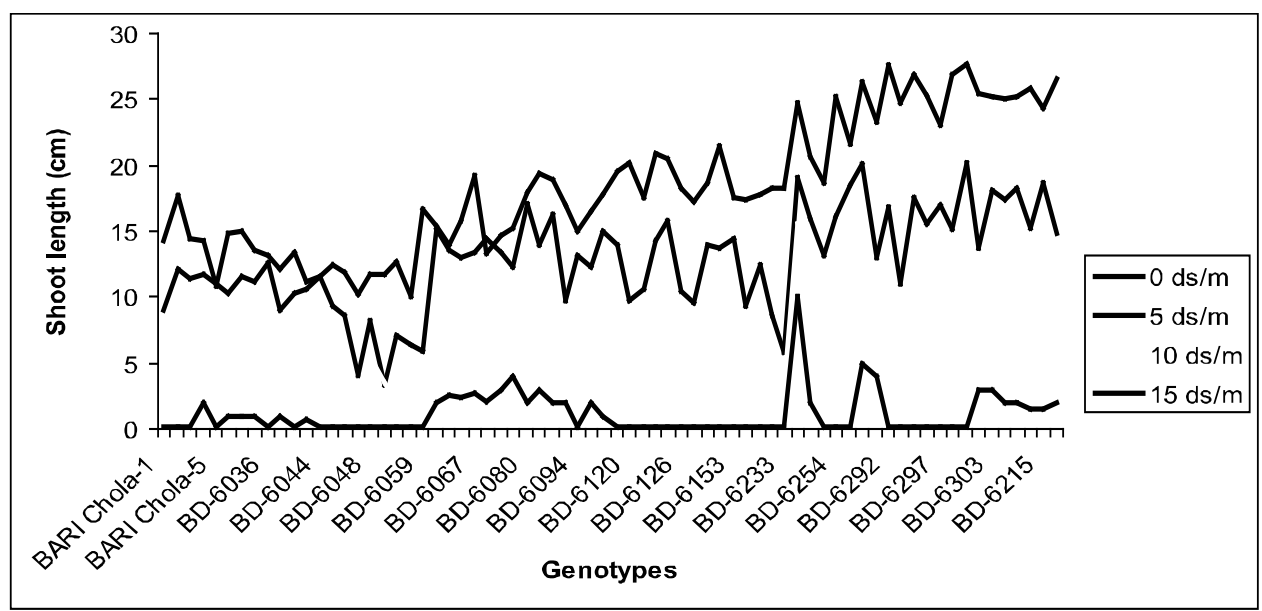

Fig. 7. Effect of salinity levels on seedling shoot length (cm) of chickpea genotypes.

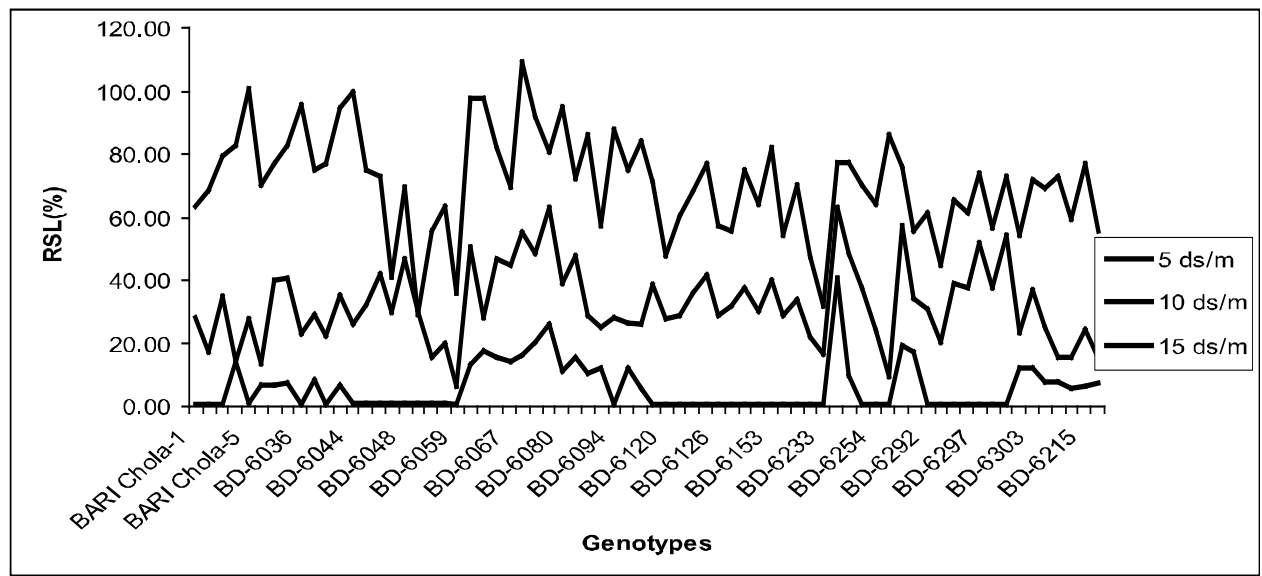

Fig. 8. Effect of salinity levels $(5,10 \& 15)$ on relative shoot lenght of chickpea genotypes.

\section{Seedling Shoot-to-Root Ratio (SRR)}

The highest SRR was found in genotype BD-6248 (150.80) followed by BD6066, BD-6297, BD-6123 and BD-6078 (Fig. 9). The lowest SRR were found in genotypes BD-6048 (48.97) followed by BD-6049 (48.83), BD-6059 (49.36), BD-6041 (56.26), BARI Chola-5 (58.89) and BD-6047 (60.58) and relative shoot-to-root ratio (RSRR) was reduced with increasing salinity levels (Fig.10). 


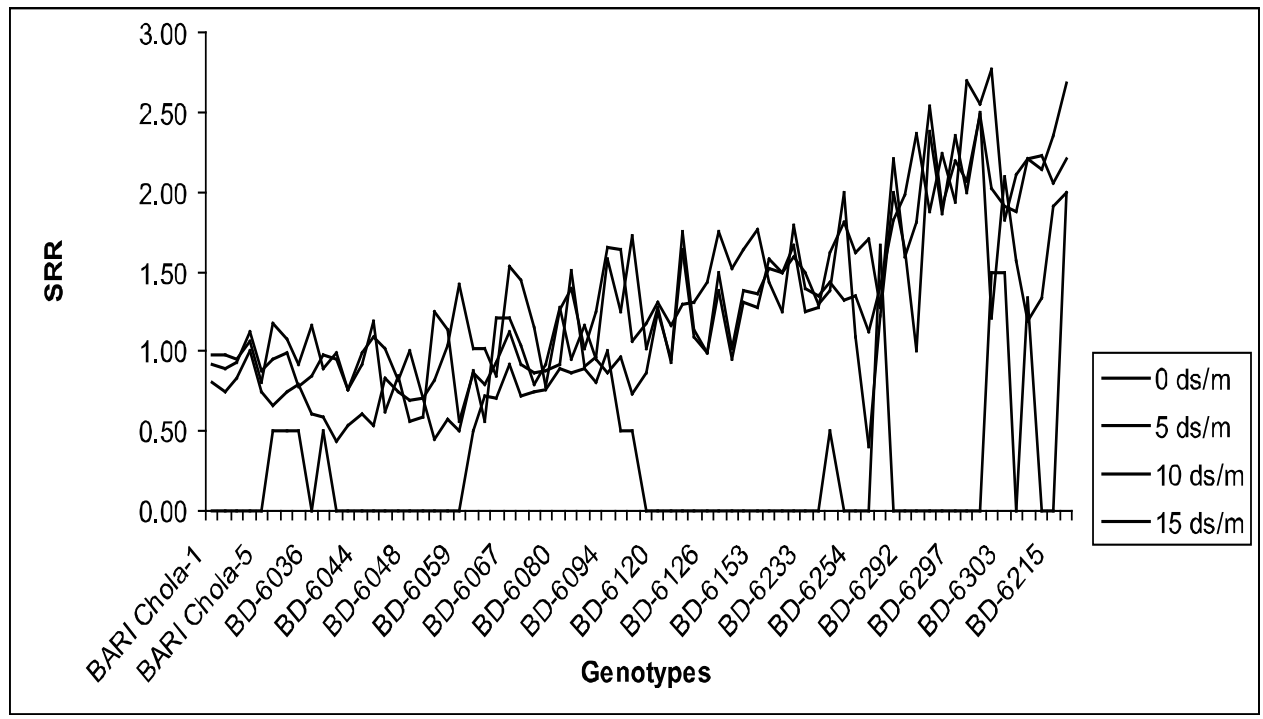

Fig. 9. Effect of salinity levels on shoot to root ratio of chickpea genotypes.

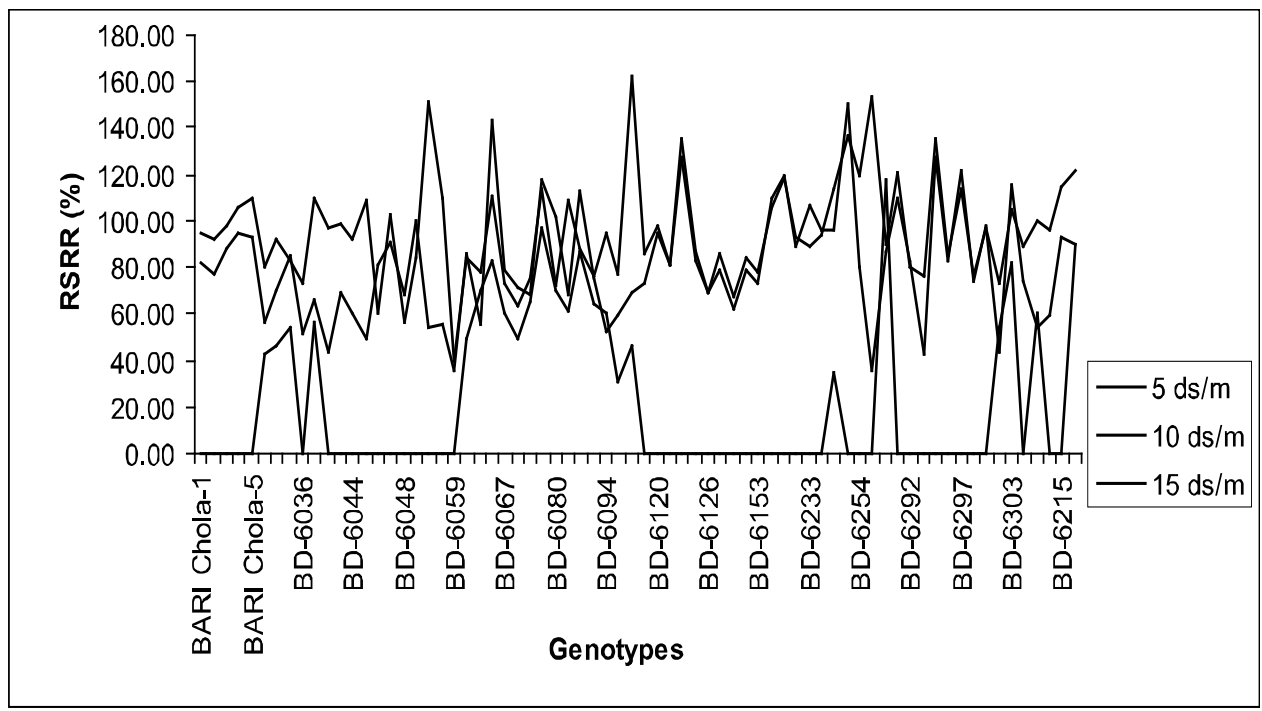

Fig. 10. Effect of salinity levels $(5,10 \& 15 \mathrm{ds} / \mathrm{m})$ on the relatives SRR of chickpea genotypes.

\section{Vigor Index}

From Fig.11, It was observed that at lower level $(5 \mathrm{ds} / \mathrm{m})$ of salinity, vigor index was influenced in some of chickpea genotypes but with increasing salinity levels, vigor index was decreased. The higher vigor index was observed in genotypes BD-6060, BD-6061, BD-6078, BD-6066, BD-6067, BD-6301 and BD-6218 at 10 
$\mathrm{ds} / \mathrm{m}$ which were grater than 500 but less than 1000 . Vigor index was decreased in some genotypes of chickpea at $15 \mathrm{dS} / \mathrm{m}$. So it indicates that chickpea was very much sensitive to salinity. Lauter and Munns (1986) reported that chickpea is susceptible to salinity, especially during germination. The results are agreement with them.

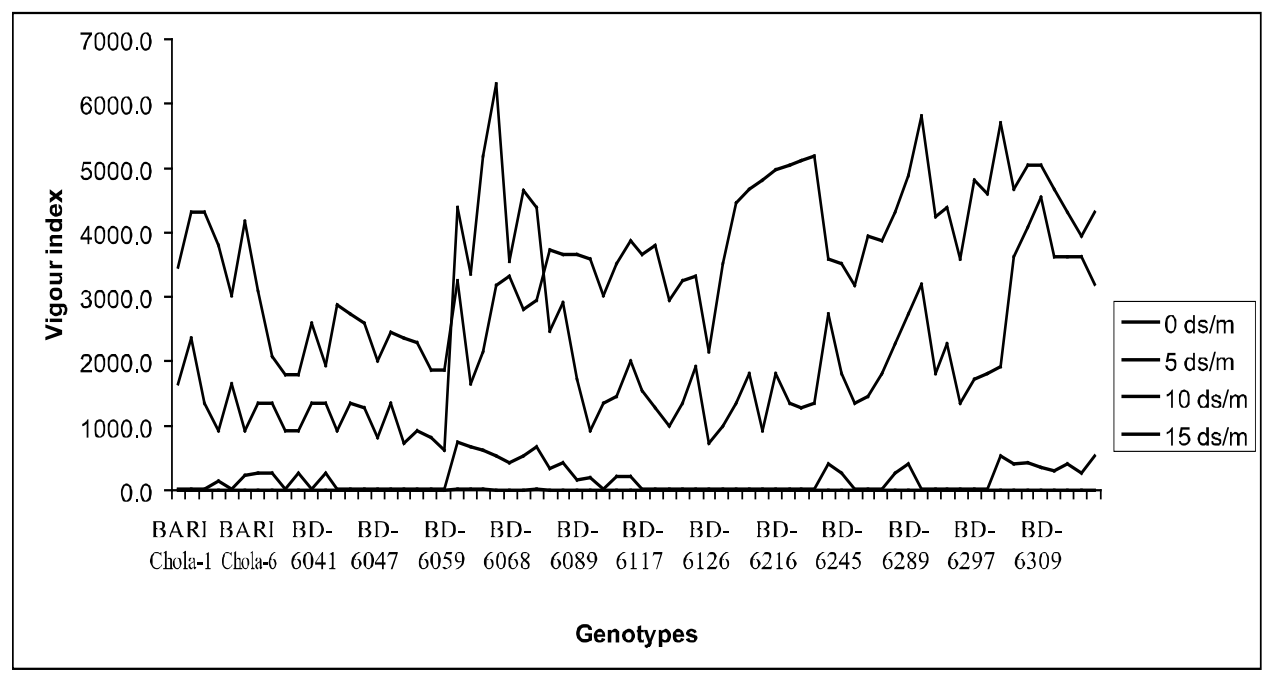

Fig. 11. Effect of salinity levels on vigour index 0f chickpea genotypes.

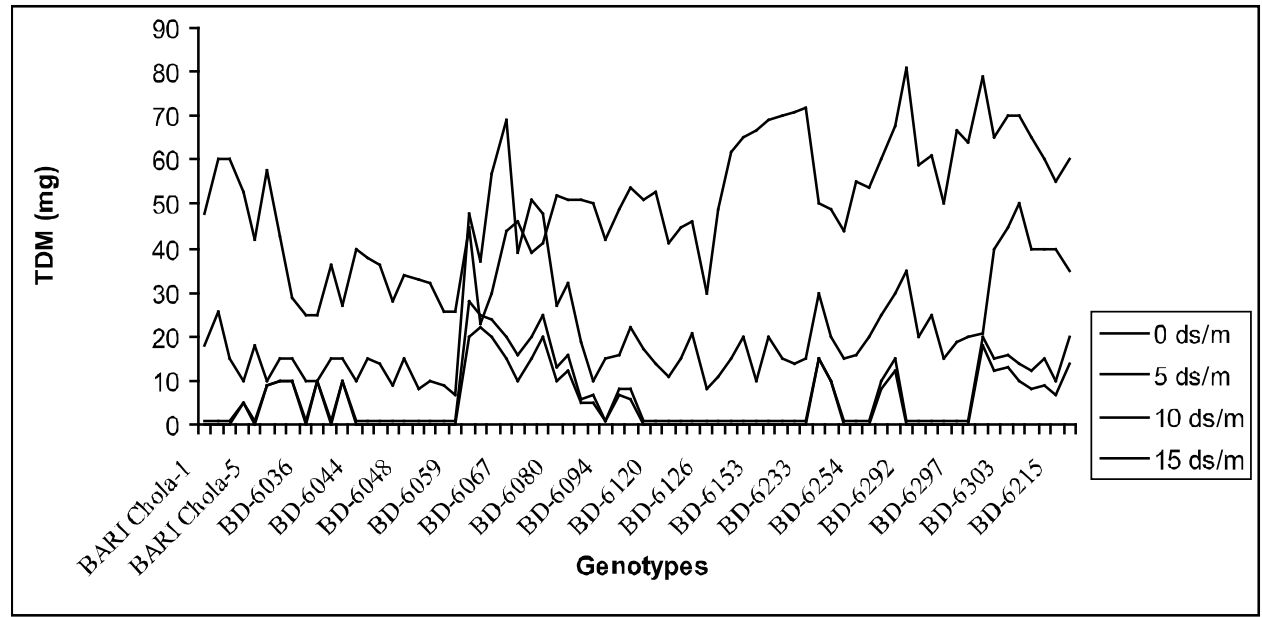

Fig. 12. Effect of salinity levels on total dry matter of chickpea genotypes. 


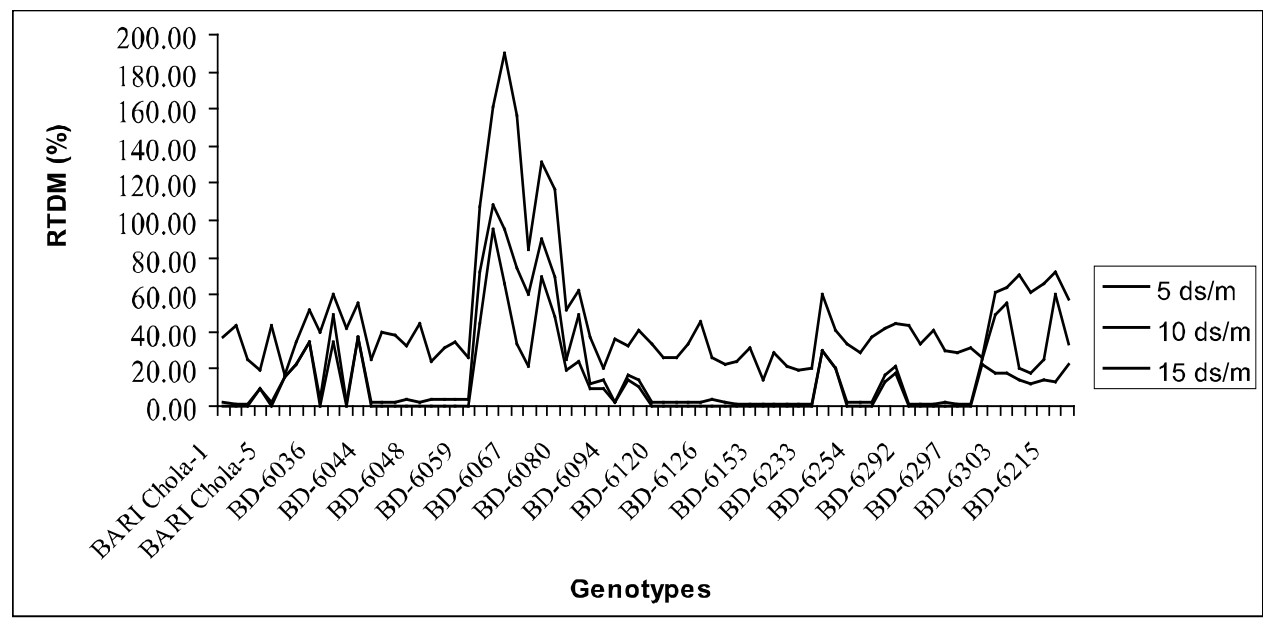

Fig.13. Effect of salinity levels on relative TDM of chickpea genotypes.

\section{Total Dry Matter}

The higher total dry matter and RTDM (Fig.13 \& Fig. 14) was observed in genotype BD-6061, BD-6066 and BD-6071 at all levels of salinity. All the genotypes were then categorized as tolerant (0-3), moderately (4 \&5), susceptible (6-7) and highly susceptible (8-9) based on 0-9 scale. The scales measured from RTDM of genotypes were as follows:

Table 1. Salinity types.

\begin{tabular}{|c|c|c|}
\hline Scale & RDM $(\%)$ & Tolerance Group \\
\hline 0 & $>120$ & Tolerant \\
1 & $110-120$ & \\
2 & $100-110$ & \\
3 & $90-100$ & Moderately Tolerant \\
\hline 4 & $80-90$ & Susceptible \\
5 & $70-80$ & \\
\hline 6 & $60-70$ & Highly Susceptible \\
7 & $50-60$ & \\
\hline 8 & $40-50$ & \\
\hline 9 & $<40$ & \\
\hline
\end{tabular}

Source: Ashraf and Waheed, 1990.

All the genotypes examined in this study were classified into ten groups based on 0-9 scale (Table.1), on the basis of their performance in relative total dry matter (RTDM). At $10 \mathrm{dS} / \mathrm{m} \mathrm{NaCl}$ there were 3 genotypes that produced greater than $90 \%$ RTDM, 3 genotypes that had 70-90 \%, 6 genotypes had 50-70 \% and 58 genotypes 
had $<50 \%$ RTDM. Among the 70 genotypes, at $10 \mathrm{dS} / \mathrm{m}$ the tolerant was $4 \%$, moderately tolerant $4 \%$, susceptible $9 \%$ and highly susceptible $73 \%$ (Fig. 14).

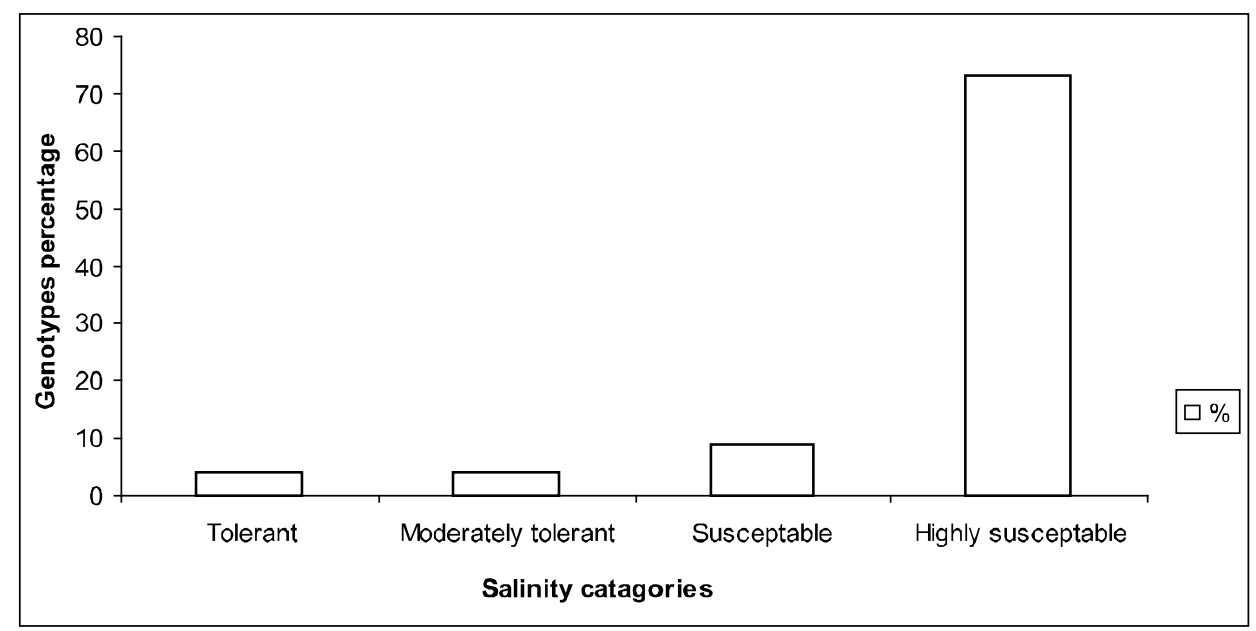

Fig. 14. Percentage of salinity tolerance of 70 chickpea genotypes.

It is now evident that the existence of genetic variation in salt tolerance is a prerequisite for development of salt tolerant cultivars through selection/ or breeding. To explore such variation in chickpea 70 genotypes were screened at the early stages, as salt tolerance throughout these stages is crucial for establishment of a crop in saline environment.

The result presented in this study deal with the salt tolerance of the genotypes at the vegetative growth stage. The tolerance observed in the 3 genotypes at 10 $\mathrm{dS} / \mathrm{m} \mathrm{NaCl}$ may or may not be conferred at the adult stage. Nevertheless, tolerance observed at the vegetative stage is of great important because it has been emphasized by many workers that the assessment of salt tolerance at vegetative stage of a plant species has considerable value in determining the ultimate tolerance of the species (Akber and Yabuno, 1974; Ashraf and McNeilly, 1987). Therefore, knowing the tolerance which was observed at vegetative stage of some genotypes would be of considerable economic value for crop establishment on salt affected soil.

\section{Conclusion}

The salt tolerant genotypes found in the diverse germplasm of chickpea could have considerable economic value in increasing yield on saline areas with moderate salinity, provided the genotypes are still tolerant when adult and also have adaptability to other factor counted in salt affected soils. The genotypes 
BD-6061, BD-6066 BD-6071, BD-6060, BD-6067 and BD 6078 should be tested in pot experiment for confirmation in the next season.

\section{References}

Abel, G. H. and A. J. MacKenzle, 1964. Salt tolerance of soybeans varieties (Glycine max L.) during germination and later growth. Crop Sci. 4: 157-161.

Al-Moaikal, R. M. S. 2006. Physiological effects of gibberellic acid and polyamine(s) on germination and seedling growth of Zea mays stressed with sodium chloride salinity. $\mathrm{Ph} . \mathrm{D}$. Thesis, Botany Dept., Science College for girls, dammam.

Ashraf, M and T. McNeilly, 1988. Variability in salt tolerance of nine spring wheat cultivars. J. Agronomy and Crop Sci. 160:14-21.

Ashraf, M. and A. Waheed.1990. Screening of local/ exotic accessions of lenti (lens culinaris Medic) for salt tolerance at two growth stage. Plant Soil, 128:167-176.

Ashraf, M. and McNeilly. T.1987.Salinity effect on five cultivers/lines of pearl millet (Pennisetum and americammum (L).Leeke).Plant and Soil. 103:13-19.

Azhar, M. F and T. McNeilly. 1987. Variability for salt tolerance in Sorghumn bicolor (L.) Moench under hydroponic conditions. J. Agronomy and Crop Sci. 159: 269-277.

Basalah, M.O. 1991. Effect of salinity on seed germination and growth of squash (Cucurbita pepo L.) seedlings. Arab Gulf J. Res. 9(2):87-97.

D'amorea, R., F. Monopli, V. Farrari, N. Acciari and G. Vitelli. 1996.valutazione agronomica di ecotipi mediterrannei di cece indue ambienti dell. Italia centroeridionale. Agricultura Ricerca, 161:13-18.

Demir M. and I. Arif. 2003. Effects of different soil salinity levels on germination and seedling growth of safflower (Carthamus tinctorius), Turk. J. Agric. 27: 221-227.

Horst, G. L and N. B. Dunning. 1989. Germination and seedling growth of perennial ryegrasses in soluble salts. J. Amer. Soc. Hort. Sci. 114(2):338-342.

Hunt, O. J. 1965. Salt tolerance in intermediate wheatgrass. Crop Sci., 5(5):407-409.

Hussain M. K. and O.U. Rehman. 1997. Evaluation of sunflower (Helianthus annuus L.) Germplasm for salt tolerance at the shoot stage. Helia. 20: 69-78.

Kumar, A.P., A. Kumar, S. N. Masih, and A. P. Shamshery. 1981. Tolerance of some barley varieties to salt stress at seedling stage. Indian J. Plant. Physiol. 24: 304-311.

Lauter, D. J. and D. N. Munns. 1986. Salt resistance of chickpea genotypes in solutions salinized with $\mathrm{NaCl}$ or $\mathrm{Na}_{2} \mathrm{So}_{4}$ Ibid, 95:271-9.

Lee, K. S., Y. S. Choi and Y. W. Choi. 1998. Varietal difference in salinity tolerance during germination stage of rice. Korean J. Crop Science 43 (1):11-14.

Lemma Desalegne. 1996. Salt Tolerance in Tomatoes (Lycopersicon esculentum Hill). A Thesis Submitted by lemma Deslegne for the Degree of Doctor of Philosophy. 
Department of Agricultural Botany, School of Plant Science, University of Reading. pp. 245.

M. A. Shahid, M. A. Pervez, R. M. Balal, T. Abbas, C. M. Ayyub, N. S. Mattson, A. Riaz and Z. Iqbal. 2012. Screening of pea (Pisum sativum L.) genotypes for salt tolerance based on early growth stage attributes and leaf inorganic osmolytes. AJCS 6(9):1324-1331.

Mahajan S. and N. Tuteja. 2005. Cold, salinity and drought stresses: An overview. Arch. Biochem. Biophys. 444: 139-158.

Mahdavi B. and S. A. Sanavy. 2007. Pakistan Journal of Biolog-ical Sciences 10(2): 273-279.

Manchanda, H. R. and S. K. Sharma. 1990. Influence of different chloride sulphate ratios on yield of chickpea (Cicer arietinum) at comparable salinity levels. Indian J. Agric Sci. 60:553-555.

Marambe, B and T. Ando. 1995. Physiological basis of salinity tolerance of sorghum seeds during germination. J. Agronomy and Crop Sci. 174:291-296.

Neumann, P.M. 1995. Inhibition of root growth by salinity stress: Toxicity or an adaptive biophysical response, In: Baluska F., Ciamporova M., Gasparikova, four species.

Paliwal, K. V. and G. L. Maliwal. 1972. Effect of salt on growth and chemical composition of okra (Abelmoschus esculentus) and sponge guard (Luffa cylindrical). J. Hort. Sci. 47: 517-524.

Petersen, L. and S. Shireen. 2001. Soil and water salinity in the coastal area of Bangladesh. SRDI.

Rahman, M.M. and M. Ahsan. 2001. Salinity constraints and agricultural productivity in coastal saline area of Bangladesh. Soil resources in Bangladesh: Assessment and Utilization.

Saxena, N.P. 1990. Status of chickpea in the Mediterranean basin. pp. 17-24. In: Proc. Present Status and Future Prospects of Chickpea Crop Production and Improvement in the Mediterranean Countries. Seminar Zaragoza (Spain). Options Mediterraneennes (CIHEAM) Serie A, 9: 11-13.

Sharma, S. K., H. R. Manchanda and J.P. Singh. 1982. Note on the performance of some chickpea varieties grown on chloride-dominant saline soils. Indian J. Agric. Sci., Sci. 52:405-407.

Singh, J. N., Sharma, D. K and Chillar, R. K. 1999. Forage yield and chemical composition of pearl millet (Pennisetum typhodes) as influenced by exchangeable sodium. J. Agric. Sci. Camb. 111(3):465-467.

Tekalign, M., C. Richter and B. Heiligatag. 1996. Response of some varieties of durum wheat and tef to salt stress. J. African Crop Sci. 4(4):423-432. 
Varshney, K. A. and B. D. Baijal. 1977. Effect of salt stress on seed germination of some pasture grasses. Crop Physi., Ecol. 2: 104-106.

Werner J. E. and R. R. Finkelstein. 1995. Arabidopsis mutants with reduced response to $\mathrm{NaCl}$ and osmotic stress, Physiol. Plant. 93: 659-666.

Yadav, H. D., O. P. Yadav, O. P. Dhankar and M. C. Oswar. 1989. Effect of chloride mineral composition of chickpea (Cicer arietimum L.) Ann., Arid Zone. 28:63-67.

Zurayk, R., M. Adlan, R. Baalbaki and M. C. Saxena, 1998. Interactive effects of salinity and biological nitrogen fixation on chickpea (Cicer arietinum L.) growth. J. Agron. Crop Sci. 180: 249-258. 